\title{
Clinicopathological Characteristics Related to Etiologies of Erythema Nodosum: A I0-Year Retrospective Study
}

\section{Preeyachat Limtong (D) Poonkiat Suchonwanit (D) Kumutnart Chanprapaph (D) Suthinee Rutnin (D)}

Division of Dermatology, Department of Medicine, Faculty of Medicine, Ramathibodi Hospital, Mahidol University, Bangkok, Thailand
Correspondence: Suthinee Rutnin Division of Dermatology, Department of Internal Medicine, Faculty of Medicine, Ramathibodi Hospital, Mahidol University, 270 Rama VI Road, Ratchathewi, Bangkok, 10400, Thailand

Tel $+662-201|I 4|$

Fax +66 2-20I-12II ext 4

Email suthinee.rutnin@gmail.com
Background: Erythema nodosum (EN) is the most common panniculitis associated with a wide variety of conditions. Updated studies regarding the clinicopathological manifestations related to etiologies of EN and its prognosis are limited.

Objective: We aimed to explore the clinicopathological features in relation to the etiologies of EN and determine characteristics of disease recurrence and its predictive factors.

Methods: A total of 169 patients with biopsy-proven EN or septal panniculitis from January 2008 to September 2018 were retrospectively reviewed. Patients were classified as either idiopathic or secondary EN. Patients' general information, clinical manifestations, investigations, and recurrence of EN were recorded. The details on histopathological findings were reviewed by a blinded dermatopathologist.

Results: The mean age at diagnosis of EN was $40.6 \pm 17.3$ years. The majority of patients $(85.2 \%)$ were female. Idiopathic EN was found in $62.7 \%$ of patients. Tuberculosis $(23.8 \%)$ and drugs $(23.8 \%)$ were the leading causes of secondary EN. In univariate logistic regression analysis, lesions on upper extremities $(\mathrm{p}=0.018)$, fever $(\mathrm{p}=0.003)$, clinical lymphadenopathy $(\mathrm{p}<0.001)$ favored secondary EN. Histopathologically, the presence of focal peripheral lobular panniculitis with eosinophils was linked to idiopathic EN ( $p=0.03$ ). However, multivariable logistic regression analysis failed to demonstrate factors associated with secondary EN. Recurrence was found in $46.6 \%$ of patients with no identifiable predictive factors.

Conclusion: Although no clinical risk factors were associated with the etiology of EN, the histopathological presence of eosinophils in focal peripheral lobular panniculitis suggested idiopathic EN.

Keywords: leg nodules, panniculitis, septal panniculitis, subcutaneous nodule, subcutaneous mass

\section{Introduction}

Erythema nodosum (EN) is the most common form of panniculitis characterized by symmetrical, erythematous, tender, warm nodules and plaques located on the pretibial areas. ${ }^{1}$ The incidence of EN is approximately one to five per 100,000 persons with a male-to-female ratio of 1:1 in children and 1:5 in adults. ${ }^{2,3}$ Although EN can occur in any age group, it is most frequently found in the second to fourth decades of life. ${ }^{4} \mathrm{EN}$ is considered a hypersensitivity response to various antigens from a wide range of precipitating factors such as infection, inflammation, neoplasm, and drugs. ${ }^{1,3,5}$ Evidence of circulating immune complexes in early lesions supports the suggestion 
that the antigen, antibody, and complement play a significant role in the pathogenesis, and circulating immune complexes may contribute to tissue injury. However, some authors have reported a lack of circulating immune complexes in uncomplicated EN, and a type IV delayed hypersensitivity reaction has been proposed. ${ }^{3}$

EN can be classified according to the etiologies as primary or idiopathic EN and secondary EN when there is an identifiable cause. ${ }^{6} \mathrm{EN}$ has also been defined histopathologically according to the chronology of lesions as acute and chronic EN. ${ }^{1,7,8}$ Approximately $32-72 \%$ of EN is idiopathic, while $28-68 \%$ is a secondary subtype. ${ }^{6,9-14}$ Conditions related to secondary EN remain inconclusive and vary according to triggering factors in the study period, ethnic, racial, and geographic differences. ${ }^{3,6,9-12}$ Regarding the clinical course, both idiopathic and secondary EN can resolve spontaneously within approximately 3-6 weeks without scarring. ${ }^{6,7}$ Few studies have shown that idiopathic EN tends to recur more frequently than secondary EN. ${ }^{6,9}$ Thus, identifying the link between clinical/histopathological parameters and the etiologies of EN to anticipate disease recurrence is important as it provides an accurate diagnosis and enables prompt management of the underlying diseases. However, there are limited studies regarding $\mathrm{EN}$ and its associated conditions. ${ }^{2,6,13,15-24}$
Moreover, studies in predictive factors link to the etiologies of EN are scarce. ${ }^{6,9,10,25}$

The primary objective of this study was to determine the clinicopathological features in relation to the etiologies of EN. Additionally, the recurrence rates and factors associated with disease recurrence were compared between primary and secondary EN.

\section{Materials and Methods}

Following the approval by the Mahidol University Review Board for Ethics in Human Research (MURA2018/885), we conducted a retrospective analytical study at the dermatology division, Ramathibodi Hospital, Mahidol University, Bangkok, Thailand from January 2008 to September 2018. The study protocol was under the Principle of the Declaration of Helsinki.

Patients diagnosed with EN based on compatible clinical manifestations and definite histopathology defined as septal panniculitis without vasculitis were included (Figure 1). ${ }^{1,7,26}$ The exclusion criteria were patients with incomplete medical and/or histopathological records, histopathological diagnoses of other types of panniculitis, and unavailable biopsy specimens for re-evaluation.

Patients' baseline characteristics (ie, age at diagnosis, gender, underlying diseases, history of prior/current medication), clinical data of $\mathrm{EN}$ (ie, onset, duration,

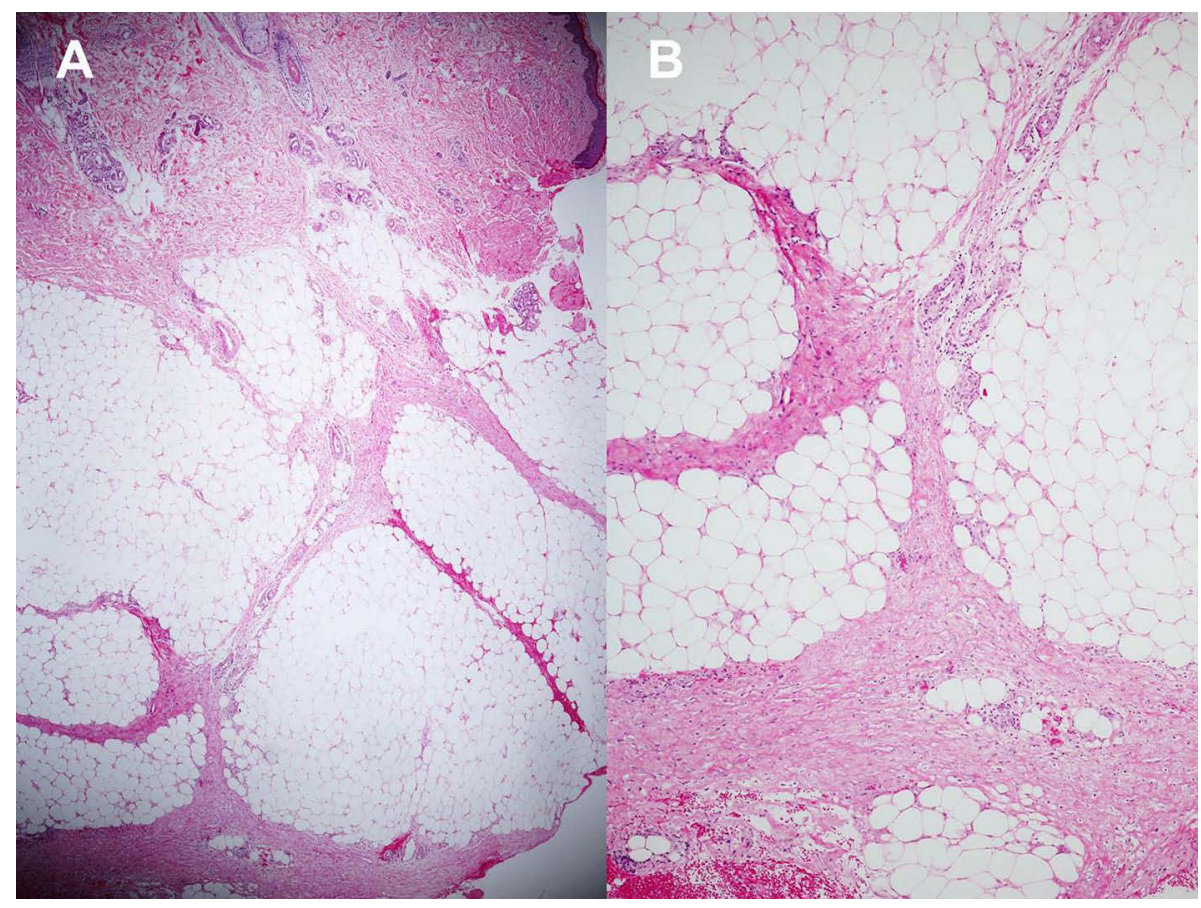

Figure I Histopathology of erythema nodosum; (A) Septal panniculitis without vasculitis (Hematoxylin-eosin stain, $x 40$ ). (B) Higher magnification demonstrating septal fibrosis with lymphohistiocytic infiltration (Hematoxylin-eosin stain, $x 100$ ). 
symptoms, morphology, color, locations), extracutaneous manifestation (ie, fever, clinical lymphadenopathy), laboratory results, chest radiographic findings, and histopathological data were retrieved from the electronic medical record system and further analyzed. Recurrence of $\mathrm{EN}$, defined as a reappearance of EN at least one month after the complete resolution, was also evaluated. ${ }^{6,9}$ Patients were further classified based on the etiologies as primary or idiopathic EN and secondary EN. Primary or idiopathic EN was defined by the absence of identifiable etiology that may lead to EN and secondary EN was diagnosed when there is an explicable cause contributing to the development of EN. ${ }^{6}$ Diagnoses of conditions and disorders leading to the development of secondary EN are as shown in Table 1. 5,6,27-42

All histopathological specimens were re-evaluated by a blinded dermatopathologist. The histopathological spectrum was chronologically classified as acute or chronic EN. Acute EN was identified when the sections revealed septal edema with hemorrhage and a prominent neutrophilic infiltration in the absence of septal fibrosis. Chronic EN was diagnosed when the histopathological sections demonstrated septal widening with fibrosis and a mixed inflammatory cellular infiltrate comprising mainly lymphocytes, histiocytes, and multinucleated giant cells. ${ }^{1,7,8}$ Additional histopathological assessments were performed from the

Table I Diagnostic Criteria for Diseases and Conditions Associated with Secondary Erythema Nodosum

\begin{tabular}{|c|c|}
\hline Diseases & Criteria for Diagnosis \\
\hline $\begin{array}{l}\text { Mycobacterium tuberculosis (TB) } \\
\text { infection }\end{array}$ & $\begin{array}{l}\text { Presence of a positive culture result or a positive nucleic acid amplification test or acid-fast bacilli found in the } \\
\text { specimen from the site of infection }{ }^{27}\end{array}$ \\
\hline $\begin{array}{l}\text { Latent tuberculosis infection } \\
\text { (LTBI) }\end{array}$ & Positive result of either the TST or IGRA without clinical symptoms of active TB infection ${ }^{27}$ \\
\hline $\begin{array}{l}\text { Disseminated tuberculosis } \\
\text { infection }\end{array}$ & Presence of evidence of hematogenous spreading of tubercle bacillii ${ }^{28}$ \\
\hline $\begin{array}{l}\text { Nontuberculous mycobacteria } \\
\text { (NTM) infection }\end{array}$ & $\begin{array}{l}\text { Consistent of clinical status, radiologic result, and repeated isolation of NTM by positive culture or nucleic } \\
\text { acid amplification test from clinical specimens (sputum, biopsy specimens, or blood) }{ }^{29,30}\end{array}$ \\
\hline Streptococcal infection & $\begin{array}{l}\text { Presence of the history of sore throat within the last } 3 \text { weeks with a positive throat swab culture or a positive } \\
\text { rapid antigen detection test or high level of } \mathrm{ASO}^{6,41}\end{array}$ \\
\hline Pseudomonas aeruginosa infection & $\begin{array}{l}\text { Considered as the cause of EN if concomitant presence of EN and positive hemoculture result and negative } \\
\text { tissue culture result of the pathogen from the EN lesion }\end{array}$ \\
\hline Cytomegalovirus (CMV) infection & $\mathrm{CMV}$ as isolated or detected from the clinical specimen ${ }^{32}$ \\
\hline $\begin{array}{l}\text { Human immunodeficiency virus } \\
\text { (HIV) infection }\end{array}$ & $\begin{array}{l}\text { Presence of demonstrable antibodies to HIV and/or HIV or one of its components was detected directly from } \\
\text { blood specimen }{ }^{33}\end{array}$ \\
\hline Mumps & Compatible clinical symptoms together with positive serological result ${ }^{34}$ \\
\hline Disseminated candidiasis & $\begin{array}{l}\text { Presence of evidences demonstrating tissue invasion by Candida spp. from histological or culture results or } \\
\text { repeated positive hemoculture results }{ }^{35}\end{array}$ \\
\hline Behçet's disease (BD) & Present of symptoms as the 1990 ISG criteria for $\mathrm{BD}^{36}$ or the 2014 ICBD criteria for $\mathrm{BD}^{37}$ \\
\hline Hematologic malignancies & $\begin{array}{l}\text { The diagnoses of myeloid, lymphoid, and myeloproliferative neoplasms were based on WHO classification } \\
\text { and cytogenetic abnormalities. }{ }^{38,39}\end{array}$ \\
\hline Sarcoidosis & $\begin{array}{l}\text { Compatible clinical features, radiological results and histopathological results of noncaseating granuloma in } \\
\text { the absence of other alternative causes of the granuloma }{ }^{42}\end{array}$ \\
\hline Drug-induced EN & $\begin{array}{l}\text { Established temporal correlation with the possible causative drugs, which contained the history of medication } \\
\text { taken before the patient developed EN and improvement of lesions after ceasing the drug, in the absence of } \\
\text { other precipitating causes } 40\end{array}$ \\
\hline
\end{tabular}

Abbreviations: ASO, anti-streptolysin-O antibody; BD, Behçet's disease; CMV, Cytomegalovirus; EN, erythema nodosum; HIV, human immunodeficiency virus; ICBD, International Criteria for Behçet's disease; IGRA, interferon-gamma release assay; ISG, International Study Group; LTBI, latent Mycobacterium tuberculosis infection; NTM, Nontuberculous mycobacteria; TB, tuberculosis; TST, tuberculin skin test; WHO, World Health Organization. 


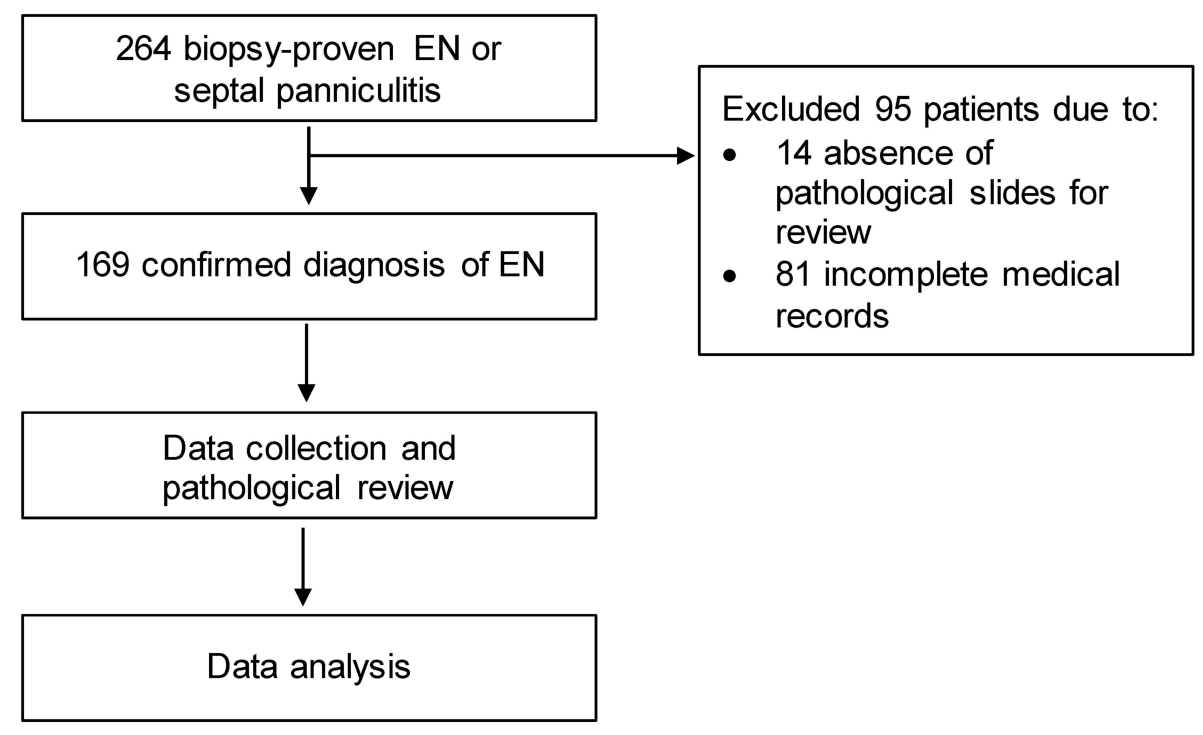

Figure 2 Recruitment process and the study flow diagram. Abbreviation: EN, erythema nodosum.

epidermis down to subcutaneous tissue. The following features were evaluated ie, epidermal changes (normal, atrophy/thinning, hyperplasia); dermal changes (distribution and pattern of cell infiltrate, cytologic composition); inflammatory patterns of the subcutaneous tissue (septal panniculitis, lobular panniculitis, mixed septal and lobular panniculitis); subcutaneous cytologic composition (lymphocytes, neutrophils, eosinophils, plasma cells, histiocytes, granuloma, extravasated erythrocytes); vasculitis; and fat necrosis.

\section{Statistical Analysis}

Statistical analyses were performed using Stata Version 14.0 (StataCorp, College Station, TX). Categorical variables were expressed as a percentage, while continuous variables were demonstrated in mean $\pm \mathrm{SD}$ for data with normal distribution and median (interquartile range, IQR) for data with non-normal distribution. According to the outcomes of our study (the etiology and recurrence of EN) which were both binary data, we utilized logistic regression analysis for evaluation of the association between each of the predictors composed of clinical manifestations, laboratory results, and histopathology. Except for clinical lymphadenopathy as a predictive factor, we applied exact logistic regression analysis due to the rarity of the variable. Multivariable logistic regression analysis was applied to the variables of which the p-value was less than 0.1 . A p-value of less than 0.05 was considered statistically significant.

\section{Results}

\section{Patients' Characteristics}

Of 264 biopsy-proven EN, 95 were excluded due to the absence of pathological slides for review $(n=14)$ and incomplete medical records $(\mathrm{n}=81)$. One hundred and sixty-nine patients remained in the study for clinical and pathological re-evaluation (Figure 2).

Demographic data, clinical features, and pathological results of EN are shown in Table 2. The mean age at diagnosis was $40.6 \pm 17.3$ years. One hundred and forty-four patients were female $(85.2 \%)$, and 25 patients were male $(14.8 \%)$. The female-to-male ratio was 5.8:1. The median time from the onset of the lesion to establishing the diagnosis of EN was 1 (0.3-3) month. The median follow-up duration was 2.3 (0.7-7.5) months. Most of the patients (75.7\%) presented with tender erythematous subcutaneous nodules. The most frequent locations were the lower extremities $(\mathrm{n}=159,94.6 \%)$, followed by the upper extremities $(\mathrm{n}=39$, $23.2 \%)$, trunk $(\mathrm{n}=11,6.5 \%)$, and face and neck region $(\mathrm{n}=6$, $3.6 \%$ ). Lesions that appeared on the bilateral shins were accounted for $68 \%$ of the patients. Concerning histopathology, the most common inflammatory cell infiltrates in the fibrous septum were lymphocytes (96.5\%), histiocytes (66.9\%), eosinophils (48.5\%d and neutrophils (43.3\%), respectively. Focal peripheral lobular panniculitis was noted in $37.9 \%$ of patients. There were no specific epidermal and dermal changes or evidence of fat necrosis on histopathology. Based on the histological spectrum, acute EN was found in 
Table 2 Demographic Data, Clinicopathological Results of Erythema Nodosum

\begin{tabular}{|c|c|}
\hline Characteristics & $(N=169)$ \\
\hline \multicolumn{2}{|l|}{ Demographic data } \\
\hline - Mean age at diagnosis (years $[ \pm S D]$ ) & $40.6 \pm 17.3$ \\
\hline \multicolumn{2}{|l|}{ - Sex; N (\%) } \\
\hline Male & $25(14.8 \%)$ \\
\hline Female & $144(85.2 \%)$ \\
\hline - Median onset of EN (months [IQR]) & I $(0.3-3)$ \\
\hline - Median follow-up duration (months [IQR]) & $2.3(0.7-7.5)$ \\
\hline - Recurrence & $55 / 118(46.6 \%)$ \\
\hline - Median time of recurrence (months $[\mathrm{IQR}]$ ) & $3(I-5.5)$ \\
\hline \multicolumn{2}{|l|}{ Symptoms of EN; $N(\%)$} \\
\hline - Asymptomatic & $17 / 165(10.3 \%)$ \\
\hline - Tenderness & $142 / 165(86.1 \%)$ \\
\hline - Pruritus & $2 / 165$ (1.2\%) \\
\hline - Tenderness and pruritus & $4 / 165(2.4 \%)$ \\
\hline \multicolumn{2}{|l|}{ Morphology; N (\%) } \\
\hline - Nodules & $128(75.7 \%)$ \\
\hline - Plaques & $52(30.8 \%)$ \\
\hline - Papules & $13(7.7 \%)$ \\
\hline - Patches & 7 (4.1\%) \\
\hline - Macules & $4(2.4 \%)$ \\
\hline - Cellulitis-like lesion & I $(0.6 \%)$ \\
\hline \multicolumn{2}{|l|}{ Color; N (\%) } \\
\hline - Red & $134(87.6 \%)$ \\
\hline - Brown & $33(21.6 \%)$ \\
\hline - Purple & 9 (5.9\%) \\
\hline - Skin-color & $5(3.3 \%)$ \\
\hline - Gray & $2(1.3 \%)$ \\
\hline \multicolumn{2}{|l|}{ Location; $\mathbf{N}(\%)$} \\
\hline - Lower extremities & $159 / 168$ (94.6\%) \\
\hline - Upper extremities & $39 / 168$ (23.2\%) \\
\hline - Trunk & II/I68 (6.5\%) \\
\hline - Face and neck & $6 / 168(3.6 \%)$ \\
\hline \multicolumn{2}{|l|}{ Pathological result of EN; $N(\%)$} \\
\hline - Acute EN & $52(30.8 \%)$ \\
\hline - Chronic EN & 117 (69.2\%) \\
\hline
\end{tabular}

Abbreviations: $E N$, erythema nodosum; IQR, interquartile range; SD, standard deviation.

52 patients (30.8\%), while chronic EN was documented in 117 patients $(69.2 \%)$.

Idiopathic EN was found in 106 patients $(62.7 \%)$, while secondary EN was documented in 63 patients (37.3\%) (Table 3). The most common identifiable etiologies for secondary EN were bacterial infections $(n=24$, $38.1 \%)$, drugs $(\mathrm{n}=15,23.8 \%)$, and hematologic malignancies $(n=9,14.3 \%)$. Among the 24 patients with bacterial
Table 3 Etiologies of Erythema Nodosum

\begin{tabular}{|c|c|}
\hline Characteristics & $(N=169)$ \\
\hline Idiopathic EN & $106(62.7 \%)$ \\
\hline Secondary EN & $63(37.3 \%)$ \\
\hline - Bacterial infections & $24(38.1 \%)$ \\
\hline ○ Mycobacterium tuberculosis & $15(62.5 \%)$ \\
\hline -TB lymphadenitis & 7 (46.7\%) \\
\hline -Pulmonary TB & $5(33.3 \%)$ \\
\hline -Latent TB infection & $2(13.3 \%)$ \\
\hline -Disseminated TB & I (6.7\%) \\
\hline o Streptococcal infection & $4(16.7 \%)$ \\
\hline o Pseudomonas infection & $4(16.7 \%)$ \\
\hline o Nontuberculous mycobacterium infection & I (4.1\%) \\
\hline \multicolumn{2}{|l|}{ - Viral infections } \\
\hline ○ CMV & $3(4.8 \%)$ \\
\hline ० HIV & I (33.3\%) \\
\hline o Mumps & I (33.3\%) \\
\hline - Fungal infection & I (33.3\%) \\
\hline o Disseminated candidiasis & $\mathrm{I}(\mathrm{I} .6 \%)$ \\
\hline - Drugs & $15(23.8 \%)$ \\
\hline o Oral contraceptive pills & $13(86.7 \%)$ \\
\hline o Others (G-CSF, Vemurafenib) & $2(13.3 \%)$ \\
\hline - Hematologic malignancies & $9(14.3 \%)$ \\
\hline$\circ \mathrm{AML}$ & $4(44.4 \%)$ \\
\hline ○ DLBCL & $3(33.3 \%)$ \\
\hline ○ CLL & I (II.I\%) \\
\hline o Primary myelofibrosis & $\mathrm{I}(\mathrm{II} .1 \%)$ \\
\hline - Behcet's disease & $5(7.9 \%)$ \\
\hline - Pregnancy & $4(6.3 \%)$ \\
\hline - Lung cancer & I (I.6\%) \\
\hline - Sarcoidosis & I (I.6\%) \\
\hline
\end{tabular}

Abbreviations: AML, acute myeloid leukemia; CLL, chronic lymphocytic leukemia; CMV, cytomegalovirus; DLBCL, diffuse large B-cell lymphoma; EN, erythema nodosum; G-CSF, granulocyte colony-stimulating factor; HIV, human immunodeficiency virus; IQR, interquartile range; SD, standard deviation; TB, tuberculosis.

infections, Mycobacterium tuberculosis (TB) was the leading culprit organism ( $\mathrm{n}=15,62.5 \%)$ with TB lymphadenitis being the most common presentation $(n=7,46.7 \%)$, followed by pulmonary tuberculosis $(n=5,33.3 \%)$. Other causative bacterial infections included streptococcal infection $(n=4,16.7 \%)$, pseudomonas infection $(n=4,16.7 \%)$, and nontuberculous mycobacterium infection $(n=1,4.1 \%)$. Oral contraceptive was the most common culprit drug for EN ( $\mathrm{n}=13,86.7 \%)$. Another two patients with druginduced EN were caused by granulocyte-colony stimulation factor (G-CSF) and vemurafenib. Among nine 
patients with EN related to hematologic malignancies, acute myeloid leukemia was the most frequent cause $(\mathrm{n}=4,44.4 \%)$, followed by diffuse large B-cell lymphoma $(\mathrm{n}=3,33.3 \%)$, chronic lymphocytic leukemia $(\mathrm{n}=1$, $11.1 \%)$, and primary myelofibrosis $(n=1,11.1 \%)$.

With regard to EN management, all secondary EN patients were treated according to the identifiable cause, including cessation of the culprit drug. Treatment was prescribed in 99 of 106 patients (93.4\%) and 44 of 63 patients $(69.8 \%)$ diagnosed with idiopathic and secondary EN, respectively. The two most common oral medications for idiopathic and secondary EN were colchicine $(83.8 \%$ VS 79.6\%) and non-steroidal anti-inflammatory drugs (NSAIDs) (74.8\% VS 70.5\%) (Table 4). Oral potassium iodide was given in refractory cases of both groups $(19.2 \%$ of idiopathic EN VS $22.7 \%$ of secondary EN). Intralesional corticosteroid injection was performed in one case of idiopathic EN. The median time of EN resolution after treatment was 5 (3-10) weeks and 4 (2-6) weeks for idiopathic and secondary $\mathrm{EN}$, respectively.

Focusing on secondary EN caused by TB infection, the median time from the onset of EN lesions to diagnoses of TB infection was $2.3(1.3-4.3)$ months, and the median

Table 4 Treatment of Erythema Nodosum

\begin{tabular}{|c|c|c|}
\hline Categories & $\begin{array}{l}\text { Idiopathic EN } \\
\qquad(N=106)\end{array}$ & $\begin{array}{c}\text { Secondary EN } \\
\qquad(N=63)\end{array}$ \\
\hline $\begin{array}{l}\text { Systemic treatment } \\
\text { - Yes } \\
\text { - No }\end{array}$ & $\begin{array}{c}99 / 106 \text { (93.4\%) } \\
7 / 106 \text { (6.6\%) }\end{array}$ & $\begin{array}{l}\text { Yes } 44 / 63(69.8 \%) \\
\text { No } 19 / 63(30.2 \%)\end{array}$ \\
\hline $\begin{array}{l}\text { Median duration to } \\
\text { resolution (weeks [IQR]) } \\
\text { - After initiation of } \\
\text { treatment } \\
\text { - Spontaneous resolution } \\
\text { without treatment }\end{array}$ & $\begin{array}{l}5(3-10) \\
3.5(1.5-4)\end{array}$ & $\begin{array}{c}4(2-6) \\
4\end{array}$ \\
\hline Systemic medication & & \\
\hline -Colchicine & 83/99 (83.8\%) & $35 / 44(79.6 \%)$ \\
\hline -NSAIDs & 74/99 (74.8\%) & $31 / 44$ (70.5\%) \\
\hline o Indomethacin & $69 / 74$ (93.2\%) & $24 / 31$ (77.4\%) \\
\hline o Naproxen & $4 / 74$ (5.4\%) & $6 / 31$ (19.4\%) \\
\hline o Diclofenac & $\mathrm{I} / 74(\mathrm{I} .4 \%)$ & $0 / 31(0 \%)$ \\
\hline o Ibuprofen & $0 / 74(0 \%)$ & $1 / 31$ (3.2\%) \\
\hline -SSKI & $19 / 99$ (19.2\%) & $10 / 44(22.7 \%)$ \\
\hline -ASA & $3 / 99(3.0 \%)$ & $0 / 44(0 \%)$ \\
\hline$-\mathrm{HCQ}$ & $1 / 99(1.0 \%)$ & $\mathrm{I} / 44(2.3 \%)$ \\
\hline
\end{tabular}

Abbreviations: ASA, acetylsalicylic acid; EN, erythema nodosum; $\mathrm{HCQ}$, hydroxychloroquine; IQR, interquartile range; NSAIDs, non-steroidal anti-inflammatory drugs; SD, standard deviation; SSKI, saturated solution of potassium iodide. time of EN resolution after initiating anti-tuberculosis drugs was 3 (2-5) months. During the treatment, 5 of 15 patients $(33.3 \%)$ found 1 episode of EN recurrence and none found recurrence after completion of the treatment.

\section{Clinicopathological Manifestations Related to Etiologies of EN}

Regarding univariate logistic regression analysis, the lesions located on the upper extremities (OR 2.42, 95\% CI [1.17, 5.01], $\mathrm{p}=0.018$, Figure 3), fever (OR 3.33, 95\% CI [1.52, 7.30], $\mathrm{p}=0.003$ ), and clinical lymphadenopathy (OR 20.8, $95 \%$ CI $[3.12, \infty], \mathrm{p}<0.001)$ were associated with secondary EN. Histopathologically, the presence of focal peripheral lobular panniculitis also favored secondary EN (OR 1.93, $95 \%$ CI $[1.01,3.65], \mathrm{p}=0.045)$. In contrast, eosinophils in focal peripheral lobular panniculitis (Figure 4), found in $60.9 \%$, was significantly related to idiopathic EN (OR $3.17,95 \%$ CI $[1.11,9.04], \mathrm{p}=0.030)$. However, there was no statistically significant association between acute/chronic EN and the etiological subtype of EN ( $p=0.578$ ), and no independent risk factors for etiologies of EN were identified after applied to multivariable analysis (Table 5).

\section{Factors Associated with Recurrence of EN}

Of a total 118 follow-up patients, recurrence was noted in 55 patients $(46.6 \%)$, being $51.4 \%(n=36)$ and $39.5 \%$ $(n=19)$ of cases with idiopathic and secondary EN, respectively. The most common conditions of secondary EN related to the highest recurrence rates were found equally in TB infection and drugs $(n=5,26.3 \%)$. There were no associations between clinical manifestations, laboratory results, histopathology, etiological subtypes of EN ( $p=$ 0.206), and the disease recurrence.

\section{Discussion}

Our study showed a predominant proportion of idiopathic EN in study subjects $(62.7 \%)$, which was comparable with previous studies (32-72\%). ${ }^{6,10-12}$ For secondary EN, the most common causes demonstrated in our study were TB infection (23.8\%) and drugs (23.8\%). The etiology of EN is variable among the studies. Prior reports noted that streptococcal infection was the leading cause of EN, ranging from $11-44 \%$. $^{3,6,10,13,15,21}$ On the contrary, previous studies from Thailand dating approximately 20 years back revealed that the most prevalent etiology was TB infection $(12 \%) .{ }^{11,12}$ As Thailand is an endemic area for $\mathrm{TB}$, the 


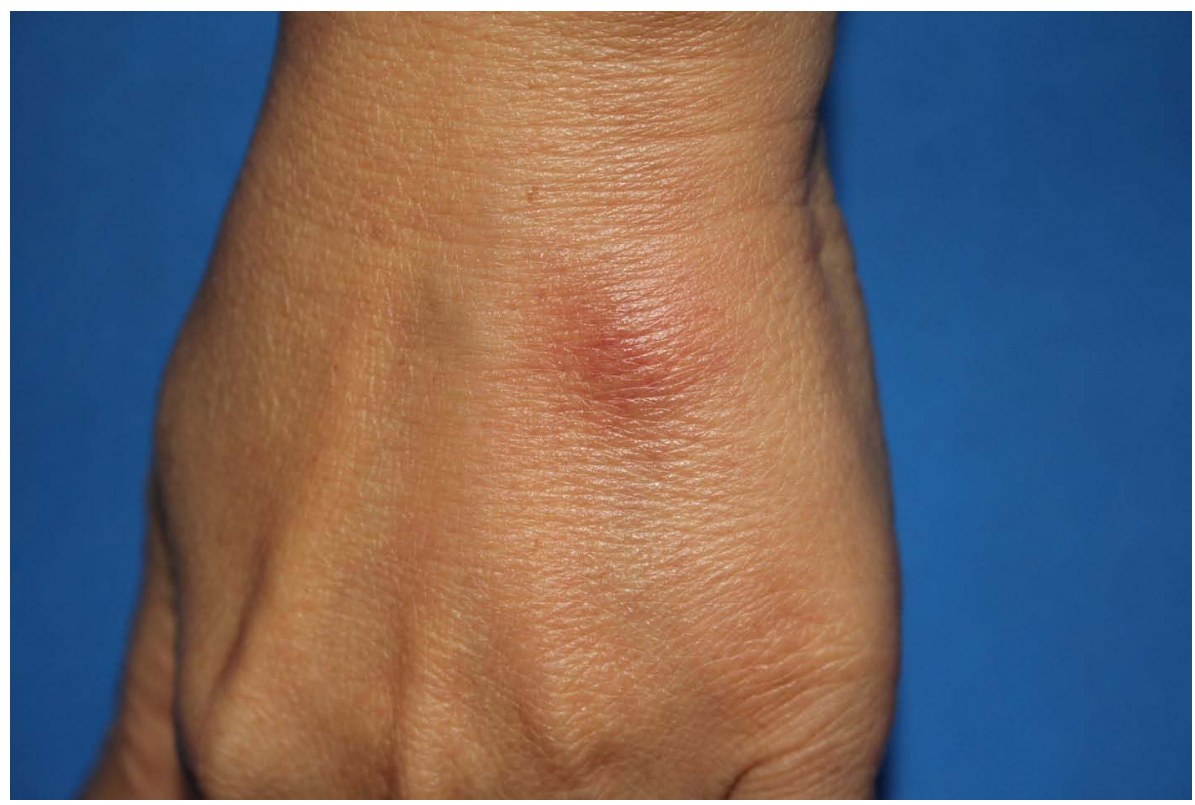

Figure 3 Erythema nodosum at the dorsum of the left hand in a patient diagnosed with acute myeloid leukemia.

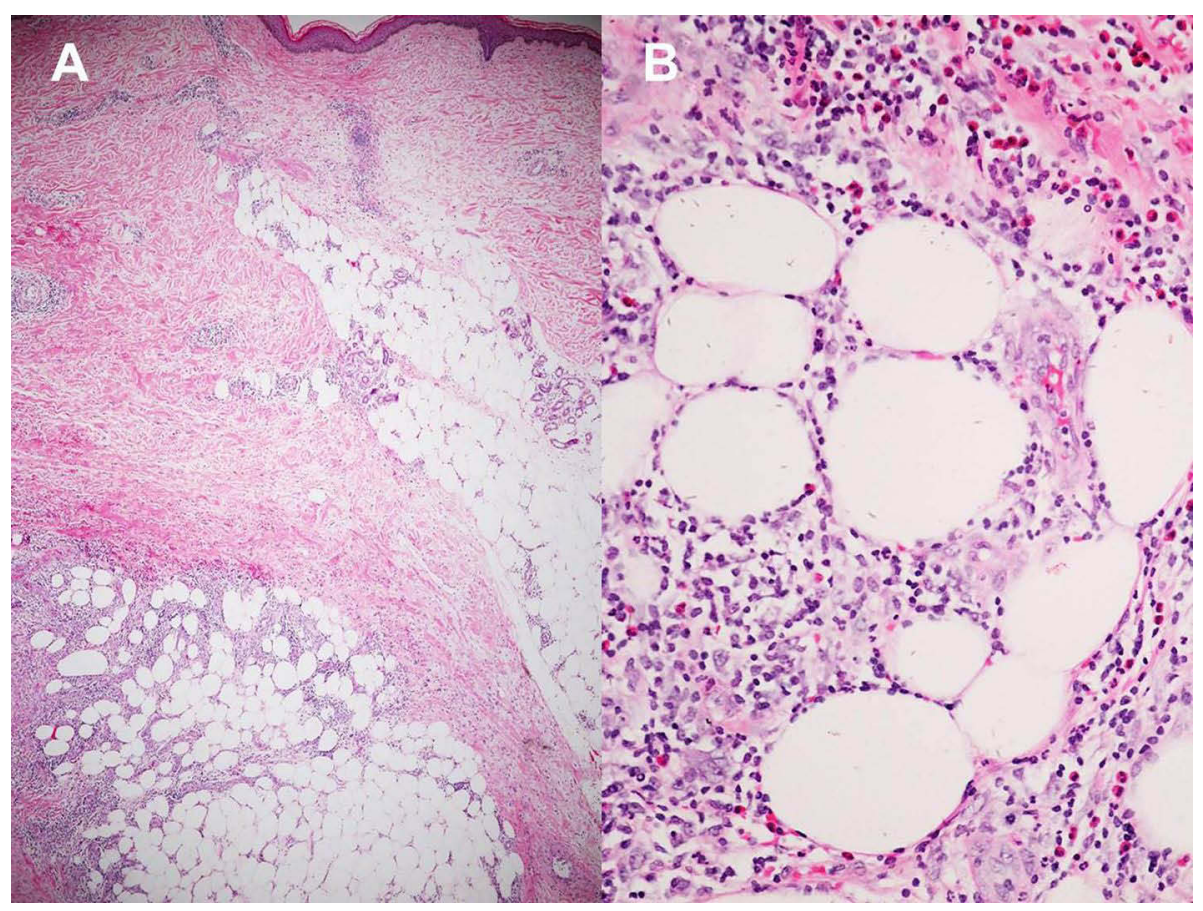

Figure 4 Histopathology of primary erythema nodosum; (A) Septal panniculitis with focal peripheral lobular infiltration (Hematoxylin-eosin stain, x40). (B) Higher magnification demonstrating numerous eosinophils in the area of focal peripheral lobular panniculitis (Hematoxylin-eosin stain, $\mathrm{x} 400$ ).

primary cause of secondary EN in our study remained the same. ${ }^{43}$ Also, Bjorn-Mortensen et al have documented that the incidence of EN increases in the TB endemic regions. ${ }^{44}$ Regarding drug-induced EN, the most common causative agent from our data was oral contraceptive pills accounting for nearly $90 \%$ of drug-induced EN. This was in line with the literature. ${ }^{4,14,40,45}$ However, two patients from our study developed EN precipitated by other drugs. Intriguingly, one of which was vemurafenib, a BRAF inhibitor, used for the treatment of melanoma, also 
Table 5 Clinicopathological Findings and Investigations in Relations to Secondary Erythema Nodosum

\begin{tabular}{|l|c|c|c|}
\hline \multirow{2}{*}{ Factors } & \multicolumn{3}{|c|}{ Logistic Regression Analysis } \\
\cline { 2 - 4 } & OR & $95 \%$ Cl & P-value \\
\hline Clinical manifestations & & & $0.018^{*}$ \\
- Presence of lesions on upper extremities & 2.42 & {$[1.17,5.01]$} & $0.003^{*}$ \\
- Fever & 3.33 & {$[1.52,7.30]$} & 0.082 \\
- Cough & 7.12 & {$[0.78,65.18]$} & 0.087 \\
- Arthralgia & 2.28 & {$[0.89,5.85]$} & $<0.00 I^{*}$ \\
- Lymphadenopathy & 20.8 & {$[3.12,-]^{\mathrm{a}}$} & \\
\hline Histopathological findings & & & \\
- Presence of focal peripheral lobular panniculitis & 1.93 & {$[1.01,3.65]$} & $0.045^{*}$ \\
- Presence of focal peripheral lobular panniculitis with & 0.32 & {$[0.11,0.90]$} & $0.030^{*}$ \\
eosinophils & & & 0.578 \\
- Chronic EN & 0.83 & {$[0.42,1.62]$} & \\
\hline
\end{tabular}

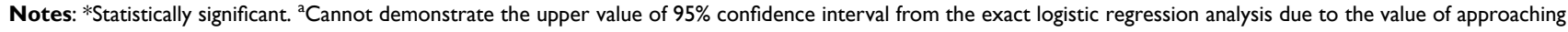
infinity.

Abbreviations: $\mathrm{Cl}$, confidence interval; $\mathrm{EN}$, erythema nodosum; OR, odds ratio.

previously reported as a possible culprit for $\mathrm{EN}^{46-49}$ Another patient developed EN precipitated by G-CSF, which has been documented in the literature as well. ${ }^{50,51}$

Treatment of EN should be directed to the underlying associated condition. The majority of the patients required only symptomatic treatments and bed rest. ${ }^{1,3,5}$ Compression bandages and limb elevation may be used for edema and pain relief. Aspirin and NSAIDs, such as indomethacin or naproxen, may be used for pain control. Colchicine has been recommended, particularly in EN patients with Behçet's disease. In refractory disease, oral potassium iodide may be prescribed. ${ }^{1,3}$ From our study, the two most common medications, including colchicine and NSAIDs, were prescribed in both idiopathic and secondary EN with good clinical response and tolerable side effects. Oral potassium iodide was given in the refractory cases, corresponding to the literature review. ${ }^{1,3}$ Other reported medications such as systemic and intralesional corticosteroids, dapsone, hydroxychloroquine, cyclosporin, and thalidomide have been used as a treatment option for EN. , $^{1,5}$

Univariate logistic regression analysis in our study showed that lesions on upper extremities were related to secondary EN $(p=0.018)$. Furthermore, the common etiologies of secondary EN presented on the upper extremities were hematologic malignancies $(\mathrm{n}=6,28.6 \%)$ and Pseudomonas aeruginosa (P. aeruginosa) infection $(\mathrm{n}=4$, $19.0 \%$ ). In general, EN typically occurs on the shins and is rarely distributed in other parts of the body, namely the thighs, forearms, and trunk. ${ }^{52}$ However, data on non- pretibial EN linked to secondary causes are still inconclusive and evidence is mainly confined to case reports/series. A study by Dogan et al stated that non-pretibial locations were significantly associated with secondary EN ( $p=$ $0.02) .{ }^{25}$ Alvarez-Lario et al revealed that EN lesions on the forearm were related to sarcoidosis and tuberculosis. ${ }^{10,53}$ Wilk et al reported three patients with EN presenting on the upper extremities, two of which were diagnosed with idiopathic EN, while the other had upper respiratory tract infection. ${ }^{52}$ Another report by Jones et al demonstrated a case of EN with lesions on the upper extremities from post-streptococcal infection. ${ }^{54}$ Our study demonstrated that atypical locations of EN, particularly on the upper extremities may have an association with secondary causes. Future prospective studies are required for this presumptive association.

Based on the clinical manifestations and investigations related to secondary EN, a study by Mert et al demonstrated that fever, leucocytosis, elevated C-reactive protein level, increased erythrocyte sedimentation rate, cough, sore throat, diarrhea, arthritis, and abnormal chest radiographic findings were significantly linked to secondary EN. ${ }^{6}$ These clinical features and laboratory findings related to secondary EN were due to post-streptococcal infection leading to acute rheumatic fever and its complications. ${ }^{6}$ The presence of fever from their study may be due to TB infection documented as one of the two most common causes of secondary EN. ${ }^{6}$ According to univariate analysis, our data revealed that fever $(\mathrm{p}=0.003)$ 
and clinical lymphadenopathy $(\mathrm{p}<0.001)$ were associated with secondary EN. TB infection was one of two main precipitating causes for secondary EN and was the most frequent etiology of secondary EN presenting with fever $(n=4,20.0 \%)$ or clinical lymphadenopathy $(n=3,37.5 \%)$ reported in our study.

This study demonstrated that the presence of tissue eosinophils on the background of focal peripheral lobular panniculitis and septal panniculitis was significantly associated with idiopathic EN ( $p=0.030)$. Early lesions of EN, eosinophils can be primarily found in the biopsy tissue. ${ }^{8,55}$ As the main etiologies of secondary EN in our study were bacterial infections (eg, TB, streptococcal, and $P$. aeruginosa infections) and inflammatory cells released to combat bacterial infection are usually neutrophils and lymphocytes rather than eosinophils, this may explain why eosinophils were less predominant on histopathological sections in cases with secondary EN. ${ }^{56-59}$

Our study showed that the histopathological classification of EN as acute or chronic was unrelated to the etiologies of EN. This result may be affected by both the duration of the lesion and the time of patient visit. As a component of inflammatory cell infiltrates varies with the age of lesions and the patient's skin biopsies were possibly not performed at the time of maximal disease intensity, misclassification of acute and chronic EN may have occurred. However, our study demonstrated that neither the diagnosis of acute/chronic EN $(p=0.234)$ nor the etiologies classified as primary/secondary $\mathrm{EN}(\mathrm{p}=1.000)$ were linked to the duration from the disease onset to the time of skin biopsy. Therefore, our results suggested a weak role between the chronological classification of $\mathrm{EN}$ on histopathology and the etiology of EN.

With regard to factors associated with EN recurrence, the study did not demonstrate significant links between clinical manifestations, laboratory results, etiology of EN, and disease recurrence. Unlike previous studies, this study's recurrence rate of secondary EN (39.5\%) was higher than previously reported $(2.1-17.9 \%) .{ }^{6.9}$ We propose that the recurrence rate may depend on the chronicity of the underlying condition. Acute infectious processes such as poststreptococcal infection and other upper respiratory tract infections required a shorter treatment duration, resulting in a lower rate of EN recurrence., ${ }^{6,9}$ While chronic diseases, such as TB required a longer treatment period and may have led to higher recurrence.

The present study is subjected to several limitations. It was analyzed retrospectively; selection and recall bias, as well as incompleteness of data, may have occurred. Besides, this was a single-center study carried out at our referral hospital. Therefore, mild cases may have been missed and patients may have had more severe underlying conditions.

\section{Conclusion}

Our study demonstrated that no significant associations between clinical manifestations and etiology of EN. However, histopathological features of focal peripheral lobular panniculitis with eosinophils in addition to the typical septal panniculitis favored idiopathic EN. Further prospective clinicopathological studies of EN from various geographical areas are recommended to validate the study outcome.

\section{Data Sharing Statement}

The data sets used to support the findings of this study are available from the corresponding author upon request.

\section{Ethics Approval and Consent to Participate}

This study was conducted in accordance with the principles of the Declaration of Helsinki. The protocol was approved by the Mahidol University Institutional Review Board for Ethics in Human Research (MURA2018/885). Informed consent was waived, and data anonymization was performed before analysis.

\section{Acknowledgments}

We would like to thank the Department of Pathology, Faculty of Medicine Ramathibodi Hospital, Mahidol University, Bangkok, Thailand for the preparation of biopsy specimens.

\section{Funding}

The authors received no financial support for this research.

\section{Disclosure}

The authors declare that they have no conflicts of interest for this work.

\section{References}

1. Requena L, Yus ES. Erythema nodosum. Dermatol Clin. 2008;26 (4):425-438, v. doi:10.1016/j.det.2008.05.014

2. Schwartz RA, Nervi SJ. Erythema nodosum: a sign of systemic disease. Am Fam Physician. 2007;75(5):695-700.

3. Pérez-Garza DM, Chavez-Alvarez S, Ocampo-Candiani J, GomezFlores M. Erythema nodosum: a practical approach and diagnostic algorithm. Am J Clin Dermatol. 2021;22(3):367-378. doi:10.1007/ s40257-021-00592-w 
4. Chowaniec M, Starba A, Wiland P. Erythema nodosum - review of the literature. Reumatologia. 2016;54(2):79-82. doi:10.5114/ reum.2016.60217

5. Patterson JW, Requena L. Panniculitis. In: Bolognia JL, Schaffer JV, Cerroni L, editors. Dermatology, 4th. Elsevier Health Sciences; 2018:1733-1757.

6. Mert A, Kumbasar H, Ozaras R, et al. Erythema nodosum: an evaluation of 100 cases. Clin Exp Rheumatol. 2007;25(4):563-570.

7. Thurber S, Kohler S. Histopathologic spectrum of erythema nodosum. J Cutan Pathol. 2006;33(1):18-26. doi:10.1111/j.03036987.2006.00402.x

8. Blake T, Manahan M, Rodins K. Erythema nodosum - a review of an uncommon panniculitis. Dermatol Online J. 2014;20(4):22376.

9. Garcia-Porrua C, Gonzalez-Gay MA, Vazquez-Caruncho M, et al. Erythema nodosum: etiologic and predictive factors in a defined population. Arthritis Rheum. 2000;43(3):584-592. doi:10.1002/ 1529-0131(200003)43:3<584::Aid-anr15>3.0.Co;2-6

10. Cribier B, Caille A, Heid E, Grosshans E. Erythema nodosum and associated diseases. A study of 129 cases. Int J Dermatol. 1998;37 (9):667-672. doi:10.1046/j.1365-4362.1998.00316.x

11. Puavilai S, Sakuntabhai A, Sriprachaya-Anunt S, Rajatanavin N, Charuwichitratana S. Etiology of erythema nodosum. J Med Assoc Thai. 1995;78(2):72-75.

12. Tantisirin O, Puavilai S. Long-term follow-up of erythema nodosum. J Med Assoc Thai. 2003;86(12):1095-1100.

13. Erez A, Horowitz J, Sukenik S. Erythema nodosum in the negev area-a survey of 50 patients. Isr J Med Sci. 1987;23(12):1228-1231.

14. Psychos DN, Voulgari PV, Skopouli FN, Drosos AA, Moutsopoulos HM. Erythema nodosum: the underlying conditions. Clin Rheumatol. 2000;19(3):212-216. doi:10.1007/s100670050159

15. Mert A, Ozaras R, Tabak F, Pekmezci S, Demirkesen C, Ozturk R. Erythema nodosum: an experience of 10 years. Scand J Infect Dis. 2004;36(6-7):424-427. doi:10.1080/00365540410027184

16. Bohn S, Büchner S, Itin P. Erythema nodosum: 112 cases. epidemiology, clinical aspects and histopathology. Schweiz Med Wochenschr. 1997;127(27-28):1168-1176.

17. Requena L, Sánchez yus E. Erythema nodosum. Semin Cutan Med Surg. 2007;26(2):114-125. doi:10.1016/j.sder.2007.02.009

18. Jones JV, Cumming RH, Asplin CM, Laszlo G, White RJ. Evidence for circulating immune complexes in erythema nodosum and early sarcoidosis. Ann N Y Acad Sci. 1976;278(1 Seventh Inter):212-219. doi:10.1111/j.1749-6632.1976.tb47032.x

19. Akdiş AC, Kiliçturgay K, Helvaci S, Mistik R, Oral B. Immunological evaluation of erythema nodosum in tularaemia. $\mathrm{Br}$ J Dermatol. 1993;129(3):275-279. doi:10.1111/j.1365-2133.1993. tb11846.x

20. Nunnery E, Persellin RH, Pope RM. Lack of circulating immune complexes in uncomplicated erythema nodosum. $J$ Rheumatol. 1983;10(6):991-994.

21. Varas P, Antúnez-Lay A, Bernucci JM, Cossio L, González S, Eymin G. Erythema nodosum: analysis of 91 hospitalized patients. Rev Med Chil. 2016;144(2):162-168. doi:10.4067/s003498872016000200003

22. Sota Busselo I, Oñate Vergara E, Pérez-Yarza EG, López Palma F, Ruiz Benito A, Albisu Andrade Y. Erythema nodosum: etiological changes in the last two decades. Pediatrics. 2004;61(5):403-407. doi:10.1016/s1695-4033(04)78414-3

23. Babamahmoudi F, Amuzgar A, Mousavi T, Davoodi L. Erythema nodosum: what should we consider about it? Caspian J Intern Med. 2016;7(4):304-305.

24. Porges T, Shafat T, Sagy I, et al. Clinical, epidemiological, and etiological changes in erythema nodosum. Isr Med Assoc J. 2018;20(12):770-772.

25. Dogan S, Karaduman A, Evans SE. Clinical and laboratory characteristics of patients with erythema nodosum. Skinmed. 2016;14 (2):99-103.
26. Requena L, Yus ES. Panniculitis. Part I. Mostly septal panniculitis. $J$ Am Acad Dermatol. 2001;45(2):163-183;quiz 184-166. doi:10.1067/mjd.2001.114736

27. Lewinsohn DM, Leonard MK, LoBue PA, et al. Official American thoracic society/infectious diseases society of America/centers for disease control and prevention clinical practice guidelines: diagnosis of tuberculosis in adults and children. Clin Infect Dis. 2017;64(2):e1e33. doi:10.1093/cid/ciw694

28. Raviglione MC. Tuberculosis. In: Kasper DL, Fauci AS, Hauser SL, Longo DL, Jameson JL, Loscalzo J, editors. Harrison's Principles of Internal Medicine. 20th ed. New York, NY: McGraw-Hill Education; 2018:1236-1259.

29. Holland SM. Nontuberculous mycobacterial infections. In: Kasper DL, Fauci AS, Hauser SL, Longo DL, Jameson JL, Loscalzo J, editors. Harrison's Principles of Internal Medicine. 20th ed. McGraw-Hill Education; 2018:1266-1270.

30. Griffith DE, Aksamit T, Brown-Elliott BA, et al. An official ATS/ IDSA statement: diagnosis, treatment, and prevention of nontuberculous mycobacterial diseases. Am J Respir Crit Care Med. 2007;175 (4):367-416. doi:10.1164/rccm.200604-571ST

31. Ramphal R. Infections due to pseudomonas, burkholderia, and stenotrophomonas species. In: Kasper DL, Fauci AS, Hauser SL, Longo DL, Jameson JL, Loscalzo J, editors. Harrison's Principles of Internal Medicine. 20th ed. New York, NY: McGraw-Hill Education; 2018:1167-1173.

32. Kotton CN, Hirsch MS. Cytomegalovirus and human herpesvirus types 6, 7, and 8. In: Kasper DL, Fauci AS, Hauser SL, Longo DL, Jameson JL, Loscalzo J, editors. Harrison's Principles of Internal Medicine. 20th ed. New York, NY: McGraw-Hill Education; 2018:1361-1366.

33. Fauci AS, Folkers GK, Lane HC. Human immunodeficiency virus disease: AIDS and related disorders. In: Kasper DL, Fauci AS, Hauser SL, Longo DL, Jameson JL, Loscalzo J, editors. Harrison's Principles of Internal Medicine. 20th ed. New York, NY: McGrawHill Education; 2018:1393-1463.

34. Rubin SA. Mumps. In: Kasper DL, Fauci AS, Hauser SL, Longo DL, Jameson JL, Loscalzo J, editors. Harrison's Principles of Internal Medicine. 20th ed. New York, NY: McGraw-Hill Education; 2018:1481-1484.

35. Edwards JEJ. Candidiasis. In: Kasper DL, Fauci AS, Hauser SL, Longo DL, Jameson JL, Loscalzo J, editors. Harrison's Principles of Internal Medicine. 20th ed. New York, NY: McGraw-Hill Education; 2018:1529-1532.

36. International Study Group for Behcet's Disease. Criteria for diagnosis of behcet's disease. Lancet. 1990;335(8697):1078-1080.

37. Davatchi F, Assaad-Khalil S, Calamia KT. International Team for the Revision of the International Criteria for Behcet's Disease (ITRICBD). The International Criteria for Behçet's Disease (ICBD): a collaborative study of 27 countries on the sensitivity and specificity of the new criteria. J Eur Acad Dermatol Venereol. 2014;28 (3):338-347. doi:10.1111/jdv.12107

38. Taylor J, Xiao W, Abdel-Wahab O. Diagnosis and classification of hematologic malignancies on the basis of genetics. Blood. 2017;130 (4):410-423. doi:10.1182/blood-2017-02-734541

39. Swerdlow SH, Campo E, Harris NL, et al. WHO Classification of Tumours of Haematopoietic and Lymphoid Tissues. International Agency for Research on Cancer; 2017.

40. Papagrigoraki A, Gisondi P, Rosina P, Cannone M, Girolomoni G. Erythema nodosum: etiological factors and relapses in a retrospective cohort study. Eur J Dermatol. 2010;20(6):773-777. doi:10.1684/ ejd.2010.1116

41. Shulman ST, Bisno AL, Clegg HW, et al. Clinical practice guideline for the diagnosis and management of group A streptococcal pharyngitis: 2012 update by the infectious diseases society of America. Clin Infect Dis. 2012;55(10):e86-e102. doi:10.1093/cid/cis629 
42. Jain R, Yadav D, Puranik N, Guleria R, Jin JO. Sarcoidosis: causes, diagnosis, clinical features, and treatments. J Clin Med. 2020;9 (4):1081. doi:10.3390/jcm9041081

43. Khan MK, Islam MN, Ferdous J, Alam MM. An overview on epidemiology of tuberculosis. Mymensingh Med J. 2019;28 (1):259-266.

44. Bjorn-Mortensen K, Ladefoged K, Simonsen J, et al. Erythema nodosum and the risk of tuberculosis in a high incidence setting. Int J Circumpolar Health. 2016;75(1):32666. doi:10.3402/ijch.v75.32666

45. Acosta KA, Haver MC, Kelly B. Etiology and therapeutic management of erythema nodosum during pregnancy: an update. Am J Clin Dermatol. 2013;14(3):215-222. doi:10.1007/s40257-013-0024-x

46. Ben-Betzalel G, Baruch EN, Boursi B, et al. Possible immune adverse events as predictors of durable response to BRAF inhibitors in patients with BRAF V600-mutant metastatic melanoma. Eur $J$ Cancer. 2018;101:229-235. doi:10.1016/j.ejca.2018.06.030

47. Degen A, Volker B, Kapp A, Gutzmer R. Erythema nodosum in a patient undergoing vemurafenib therapy for metastatic melanoma. Eur J Dermatol. 2013;23(1):118. doi:10.1684/ejd.2012.1915

48. Sinha R, Edmonds K, Newton-Bishop J, Gore M, Larkin J, Fearfield L. Erythema nodosum-like panniculitis in patients with melanoma treated with vemurafenib. J Clin Oncol. 2013;31(19): e320-e321. doi:10.1200/jco.2012.45.8307

49. Mossner R, Zimmer L, Berking C, et al. Erythema nodosum-like lesions during BRAF inhibitor therapy: report on 16 new cases and review of the literature. J Eur Acad Dermatol Venereol. 2015;29 (9):1797-1806. doi:10.1111/jdv.13039

50. Nomiyama J, Shinohara K, Inoue H. Erythema nodosum caused by the administration of granulocyte colony-stimulating factor in a patient with refractory anemia. Am J Hematol. 1994;47(4):333. doi:10.1002/ajh.2830470420
51. George S, George B, Gorak E. Erythema nodosum secondary to granulocyte colony-stimulating factor in a patient with hodgkin lymphoma during CD34+ cell mobilization for autologous peripheral blood stem cell transplantation: a dose-mediated effect. Biol Blood Marrow Transplant. 2005;11(10):816-817. doi:10.1016/j.bbmt.2005.07.003

52. Wilk M, Zelger BG, Hayani K, Zelger B. Erythema nodosum, early stage - a subcutaneous variant of leukocytoclastic vasculitis? Clinicopathological correlation in a series of 13 patients. Am J Dermatopathol. 9000. Publish Ahead of Print. doi:10.1097/ dad.0000000000001469

53. Alvarez Lario B, Piney E, Rodríguez-Valverde V, Peña Sagredo JL, Peiró Callizo E. Eritema nudoso: estudio de 103 casos [Erythema nodosum: study of 103 cases]. Med Clin (Barc). 1987;88(1):5-8. Spanish.

54. Jones M, de Keyser P. Rash on the arms and legs. BMJ. 2015;351: h4131. doi:10.1136/bmj.h4131

55. Adame J, Cohen PR. Eosinophilic panniculitis: diagnostic considerations and evaluation. J Am Acad Dermatol. 1996;34(2 Pt 1):229-234. doi:10.1016/s0190-9622(96)80117-4

56. Chaplin DD. Overview of the immune response. J Allergy Clin Immunol. 2010;125(2 Suppl 2):S3-S23. doi:10.1016/j.jaci.2009.12.980

57. de Martino M, Lodi L, Galli L, Chiappini E. Immune response to mycobacterium tuberculosis: a narrative review. Front Pediatr. 2019;7:350. doi:10.3389/fped.2019.00350

58. Davido B, Makhloufi S, Matt M, et al. Changes in eosinophil count during bacterial infection: revisiting an old marker to assess the efficacy of antimicrobial therapy. Int J Infect Dis. 2017;61:62-66. doi:10.1016/j.ijid.2017.06.005

59. Ramirez GA, Yacoub M-R, Ripa M, et al. Eosinophils from physiology to disease: a comprehensive review. Biomed Res Int. 2018;2018:28. doi:10.1155/2018/9095275

\section{Publish your work in this journal}

Clinical, Cosmetic and Investigational Dermatology is an international, peer-reviewed, open access, online journal that focuses on the latest clinical and experimental research in all aspects of skin disease and cosmetic interventions. This journal is indexed on CAS
The manuscript management system is completely online and includes a very quick and fair peer-review system, which is all easy to use. Visit http://www.dovepress.com/testimonials.php to read real quotes from published authors. 